\title{
A Study of Estimation of Learners' Understanding on Intellectual Property using Categorized Questions
}

\author{
Hiroshi Murai, Toshihiro Hayashi, Rihito Yaegashi, Ken'ichi Fujimoto, and Naka Gotoda
}

\begin{abstract}
In this paper, we examine the design and implementation of an e-learning system to support intellectual-property (IP) education. The system consists of three functions: examination of online test using categorized questions, measurement of four academic skills of learners and classification of learner's understanding to recommend suitable learning contents for the learner. With the categorized questions in the examination function, we measure four learner's academic skills and classify the learner to one of six understanding types. From the classification results, the system makes a judgment which contents should be suitable for the learner. The learners can study by themselves using the contents. The system was implemented in an introductory course of on-demand e-Learning at five universities in Japan. The experimental results show that the proposed system is useful for classification of learners' understanding type. Further research on this type of learning support system would contribute to development of the recommender system on IP education.
\end{abstract}

Keywords - e-learning, law education, learning support, intellectual-property education

\section{INTRODUCTION}

There have been many developments on learning support system that recommend suitable learning contents for learners [1]-[7]. These systems are designed to be intelligent in analyzing learners' understanding.

In the past research, we developed a learning-support system with a classification function that can classify learners' understanding into six types using results of online test [3], [4] and [6]. According to these types, the system recommended the suitable learning contents for the learner automatically. In addition, we inspected the usefulness of the proposed system in the lecture of the real network technology [3] and [4]. We also showed the system could be applicable on the law education [4] and the usefulness of the quiz application to estimate the learners' understanding on IP education [5] and [6].

In this paper, we propose an e-learning system that measures academic skills of learners using categorized questions and estimates learners' understanding using the skills.

Manuscript received May 10, 2016. This work was supported by JSPS KAKENHI Grant Number 15K00483.

H. Murai is with Kagawa University, Takamatsu 760-8521, Japan

T. Hayashi is with Kagawa University, Takamatsu 760-8521, Japan

R. Yaegashi is with Kagawa University, Takamatsu 760-8521, Japan.

K. Fujimoto is with Kagawa University, Takamatsu 760-8521, Japan

N. Gotoda is with Kagawa University, Takamatsu 760-8521, Japan

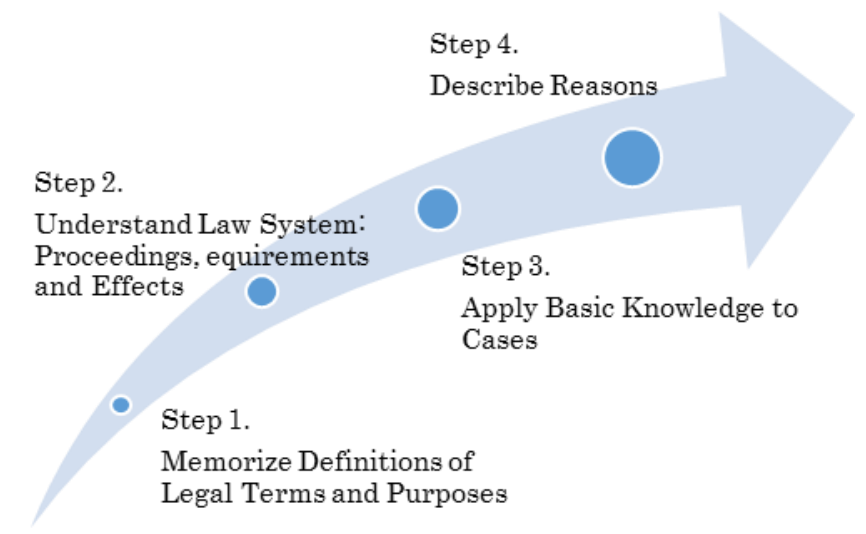

Fig. 1. Step-by-Step Learning on IP Education

\section{BACKGROUNDS}

Fig.1 shows that there are four steps in the introductory phase of the IP education. The taxonomy of this educational objectives in the flow is according to Bloom's Taxonomy: Knowledge, Understanding, Applying and Analyzing [8].

First, learners start with an acquirement of knowledge such as the definition of legal terms or the purpose of the law and legal system. To disturb that the learner uses a legal term by selfish interpretation, the important legal terms are defined by law. In legal documents such as precedent, lawyers generally use expressions including phrases and keywords that describe the aims of provisions where the phrases and keywords are carefully selected by legal experts. The learners are trained to use the phrases and keywords. Likely, it is important to understand the law system: legal proceedings, requirements and effects, too.

Next, teachers instruct how to apply the acquired knowledge to solving case problems with the reasons. Since there is different learning method for each step, we need to categorize the questions according to the step beforehand. In addition, it is necessary to make estimation criteria of learners' understanding without depending on the results of both the categorization or difficulty of the questions.

\section{Methodology}

\section{A. Proposed System}

Fig. 2 shows the estimation flow of learners' understanding using categorized questions on IP education. The proposed system consists of three functions: examination of online test 


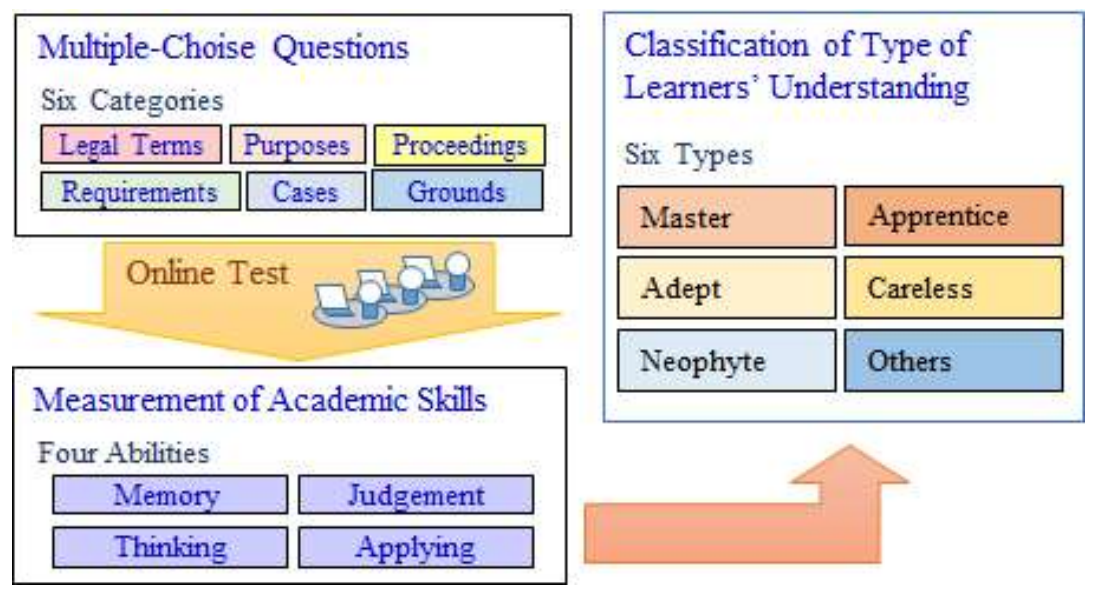

Fig. 2. Estimation flow of learners' understanding of IP

using categorized questions, measurement of learner's four academic skills and classification of learner's understanding type to recommend suitable learning contents for the learner.

At first, the online test that consists of multiple-choice questions is implemented on the e-Learning server. Next, the measurement function measures four academic skills of a learner, such as memory, judgement, thinking and applying, using the correct answer ratio as the results of online test. The skills are selected by both basic skill and three academic skills that are provided in Article 30(2) of the Japanese School Education Act. Finally, the type of learners' understanding is classified to six types: Master, Apprentice, Adept, Careless, Neophyte and Others.

TABLE I: THE CATEGORIZED QUESTIONS

\begin{tabular}{|c|c|c|c|}
\hline Category Name & \multicolumn{2}{|l|}{ Learning Step } & \multirow{2}{*}{$\begin{array}{l}\text { Learning Objectives } \\
\text { A) Memorize the meaning of legal } \\
\text { terms. } \\
\text { B) Distinction of the similar legal } \\
\text { terms. }\end{array}$} \\
\hline $\begin{array}{l}\text { 1) Questions } \\
\text { Legal Terms } \\
\text { 2) Questions } \\
\text { Purposes }\end{array}$ & $\begin{array}{l}\text { Memorize } \\
\text { Definitions of } \\
\text { Terms and Pur }\end{array}$ & $\begin{array}{l}\text { Legal } \\
\text { oses }\end{array}$ & \\
\hline $\begin{array}{l}\text { 3) Questions } \\
\text { Requirements }\end{array}$ & $\begin{array}{l}\text { Understand } \\
\text { System: } \\
\text { Proceedings, } \\
\text { Requirements } \\
\text { Effects, } \\
\end{array}$ & and & $\begin{array}{l}\text { A) Reproduction of the key } \\
\text { phrase about purpose of the law } \\
\text { system exactly. } \\
\text { B) Enumeration of important } \\
\text { requirements exactly. }\end{array}$ \\
\hline $\begin{array}{l}\text { 4) Questions } \\
\text { Applications } \\
\text { 5) Questions } \\
\text { Proceedings }\end{array}$ & $\begin{array}{l}\text { Apply } \\
\text { Knowledge to }\end{array}$ & $\begin{array}{l}\text { Basic } \\
\text { Cases }\end{array}$ & $\begin{array}{l}\text { A) Explanation of the legal terms } \\
\text { that are not defined by the text } \\
\text { exactly. } \\
\text { B) Explanation of important } \\
\text { proceedings without losing } \\
\text { requirements or key phrases. }\end{array}$ \\
\hline $\begin{array}{l}\text { 6) Questions } \\
\text { Justifications }\end{array}$ & Describe Reaso & & $\begin{array}{l}\text { A) Description using key phrases } \\
\text { of important text and commonly } \\
\text { accepted view. }\end{array}$ \\
\hline \multicolumn{4}{|c|}{ TABLE II: THE SAMPLE QUESTIONS } \\
\hline $\begin{array}{l}\text { Category } \\
\text { Names }\end{array}$ & Question & Ans & \\
\hline $\begin{array}{l}\text { Questions on } \\
\text { Legal Terms }\end{array}$ & $\begin{array}{l}\text { What is an } \\
\text { "invention" in the } \\
\text { Patent Act? }\end{array}$ & $\begin{array}{l}\text { The } \\
\text { "tec } \\
\text { natu }\end{array}$ & $\begin{array}{l}\text { "highly advanced" "creation" of } \\
\text { aical ideas" "utilizing the laws of } \\
\text { e". }\end{array}$ \\
\hline $\begin{array}{l}\text { Questions on } \\
\text { Purposes }\end{array}$ & $\begin{array}{l}\text { Explain a } \\
\text { reproduction in the } \\
\text { private use. }\end{array}$ & $\begin{array}{l}\text { "Per } \\
\text { purp } \\
\text { the } 2 \\
\text { othe }\end{array}$ & $\begin{array}{l}\text { nally or in-home", in the case of a } \\
\text { se, a copyright holder can reprint } \\
\text { e in a limited range following these } \\
\text { "without permission". }\end{array}$ \\
\hline
\end{tabular}

\section{B. Categorized questions}

In this paper, we classify the questions to six categories with learning objectives corresponding to the learning steps on the IP education illustrated in Table I.

Table II shows sample questions that important keywords are bound in " " in their answers. The learning method that consists of a question-and-answer section is applicable to knowledge acquisition on law education.

Questions on Legal Terms are useful to memorize definition of legal terms at the first learning step. Questions on Purposes and Questions on Requirements ask knowledge whether the learner can use the important key phrases and enumerate the important requirements exactly. In this paper, we made similar choices in the phase of making questions in order to ask the skill of not memory but judgement.

\section{How to Measure Learners' Academic Skills}

As we described in subsection $A$, we measure four academic skills of learners to estimate their understanding such as memory, judgement, thinking, and applying. Table III shows the elements of a weight matrix $w_{k j}$ for the $j$ th category to calculate the academic skills $r_{k}$. In this paper, we determined

TABLE III: WEIGHTS TO MEASURE LEARNER'S ACADEMIC SKILLS

\begin{tabular}{llcccc}
\hline \hline \multirow{2}{*}{ Category $j$} & \multicolumn{2}{c}{ Weights } & $w_{k j}$ for Academic Skills $r_{k}$ & \\
& $\begin{array}{l}\text { Memory } \\
r_{0}\end{array}$ & $\begin{array}{l}\text { Judgement } \\
r_{l}\end{array}$ & $\begin{array}{l}\text { Thinking } \\
r_{2}\end{array}$ & $\begin{array}{l}\text { Applying } \\
r_{3}\end{array}$ \\
\hline 0 & Legal Terms & 0.20 & 0.07 & 0.06 & 0.09 \\
\hdashline 1 & Purposes & 0.15 & 0.14 & 0.06 & 0.18 \\
\hline 2 & Requirements & 0.15 & 0.29 & 0.06 & 0.09 \\
\hline 3 & Applications & 0.10 & 0.14 & 0.29 & 0.18 \\
\hline 4 & Proceedings & 0.20 & 0.21 & 0.24 & 0.18 \\
\hline 5 & Descriptions & 0.20 & 0.14 & 0.29 & 0.27 \\
\hline \hline
\end{tabular}

TABLE IV: SAMPLE DATA OF CORRECT ANSWER RATIO

\begin{tabular}{|c|c|c|}
\hline \multicolumn{2}{|c|}{ Category $j$} & Correct Answer Ratio $\theta_{i j}$ \\
\hline 0 & Terms & 0.67 \\
\hline 1 & Purposes & 0.83 \\
\hline 2 & Requirements & 0.75 \\
\hline 3 & Applications & 0.88 \\
\hline 4 & Proceedings & 0.86 \\
\hline 5 & Descriptions & 0.50 \\
\hline
\end{tabular}


TABLE V: EXPLANATION OF LEARNER'S TYPE

\begin{tabular}{l:l:l}
\hline \hline Category & Explanation \\
\hline $\mathrm{A}$ & Master & Learner who achieved excellent results. \\
\hdashline $\mathrm{B}$ & Adept & $\begin{array}{l}\text { Learner who acquired basic knowledge but was not good } \\
\text { at the thinking. }\end{array}$ \\
\hdashline $\mathrm{C}$ & Careless & $\begin{array}{l}\text { Learner who acquired basic knowledge but was not good } \\
\text { at the judgement. }\end{array}$ \\
\hdashline $\mathrm{D}$ & Apprentice & Learner who memorized the meaning of the legal terms. \\
\hdashline $\mathrm{E}$ & Neophyte & Learner who started learning. \\
\hdashline $\mathrm{F}$ & Others & \\
\hline \hline
\end{tabular}

TABLE VI: PICKUP FLOW OF LEARNER'S TYPE

\begin{tabular}{|c|c|c|}
\hline Step & Pickup Type & Pickup Condition \\
\hline 1 & Neophyte & $\begin{array}{l}\text { Correct answer ratio of questions of legal terms was } \\
\text { under } 0.6 \text {. }\end{array}$ \\
\hline 2 & Apprentice & All skills were under 0.6 . \\
\hline 3 & Master & $\begin{array}{l}\text { All skills were } 0.8 \text { and over, or average of correct } \\
\text { answer ratio of all questions is } 0.8 \text { and over. }\end{array}$ \\
\hline 4 & Careless & $\begin{array}{l}\text { Lowest skill was Judgement among three skills, such } \\
\text { as Memory, Judgement and Thinking. }\end{array}$ \\
\hline 5 & Adept & $\begin{array}{l}\text { Lowest skill was Thinking among three skills, such as } \\
\text { Memory, Judgement and Thinking. }\end{array}$ \\
\hline 6 & Others & \\
\hline
\end{tabular}

the weight values by trial and error. For example, since memory skill is the most important of all skills to solve questions on legal terms, we set it to a high value for memory in the category 0 .

The values of the academic skills $r_{k}$ are calculated by (1). The parameter $\theta_{j}$ represents the correct answer ratio of a learner for category $j$.

$$
r_{k}=\sum_{j=0}^{5} \theta_{j} \cdot w_{k j}
$$

We illustrate a sample data of correct answer ratio $\theta_{i j}$ of learner $i$ in Table IV.

\section{Estimation of Learners' Understanding}

We defined six types of learners' understanding based on their academic skills in Table $\mathrm{V}$, and the pickup flow of the type of learners' understanding also in Table VI.

We can estimate the type of the learners' understanding based on their academic skills calculated by the measurement function. It performs more detailed analysis using academic skills than the score of online test.

TABLE VII: SUMMARY OF ONLINE COURSE

\begin{tabular}{ll}
\hline \hline & Explanation \\
\hline Course Name & Local contents and Intellectual Property Management \\
\hdashline Learning Style & on-demand e-Learning \\
\hdashline No. of Learners & 199 \\
\hline No. of Questions & 30 \\
& $\begin{array}{l}\text { Terms: 3, Purposes: 6, Requirements: 4, Applications: 8, } \\
\text { Proceedings: 7, Descriptions: 2 }\end{array}$ \\
\hline \hline
\end{tabular}

\section{RESUltS AND DisCUSSION}

The proposed system was implemented in an introductory course of on-demand e-Learning at five universities in Japan. The summary of the online course is illustrated in Table VII. The number of learners is 199 and that of questions is 30 .

We show the estimation results in Fig. 3 to 5. Fig. 3 illustrates the distribution of the number of learners for each category corresponding to their correct answer ratio. A peak of category "Questions of Legal Terms" is the highest and becomes the order of "Purposes", "Applications", "Requirements", "Proceedings", "Justifications", as follows. Since they are distributed in the order of difficulty of the questions, we consider that the difficulty and categorization of questions is valid.

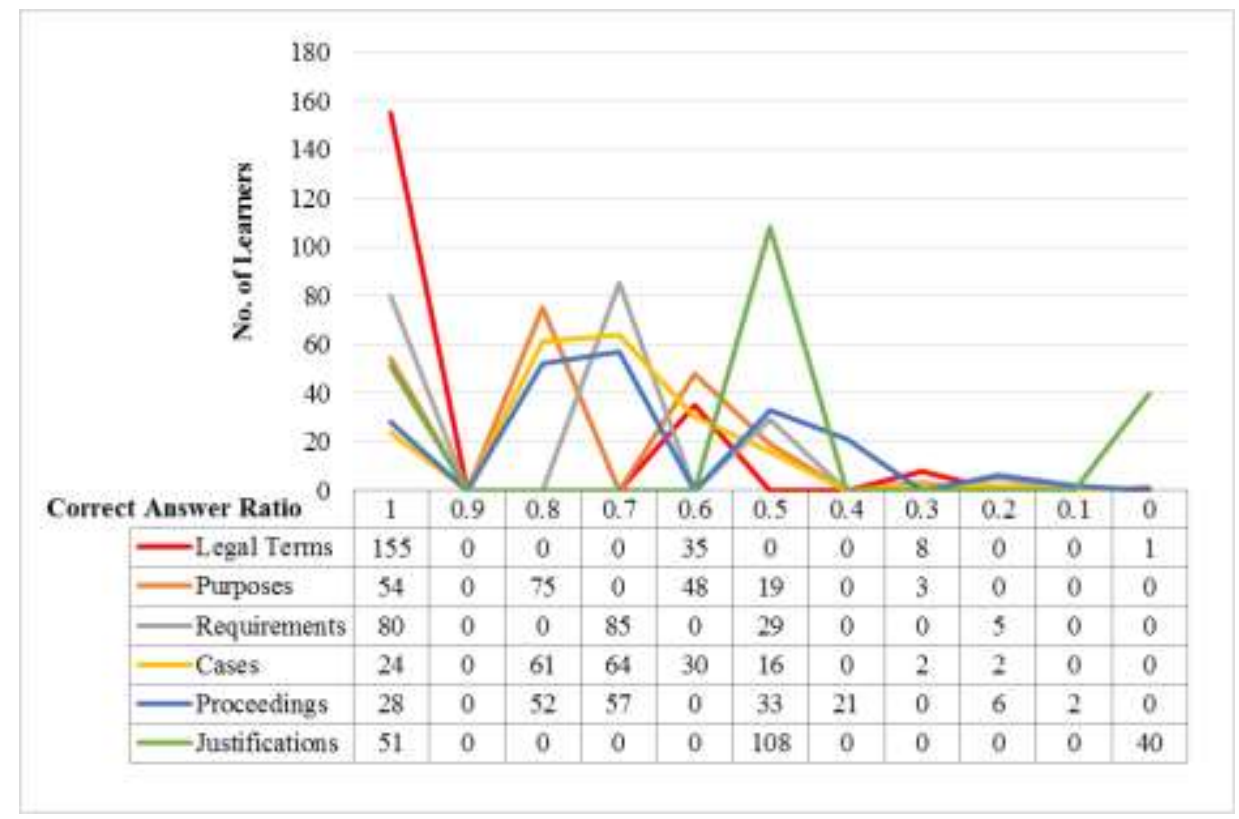

Fig. 3. No. of Learners' Distribution of Correct Answer Ratio for Each Category 


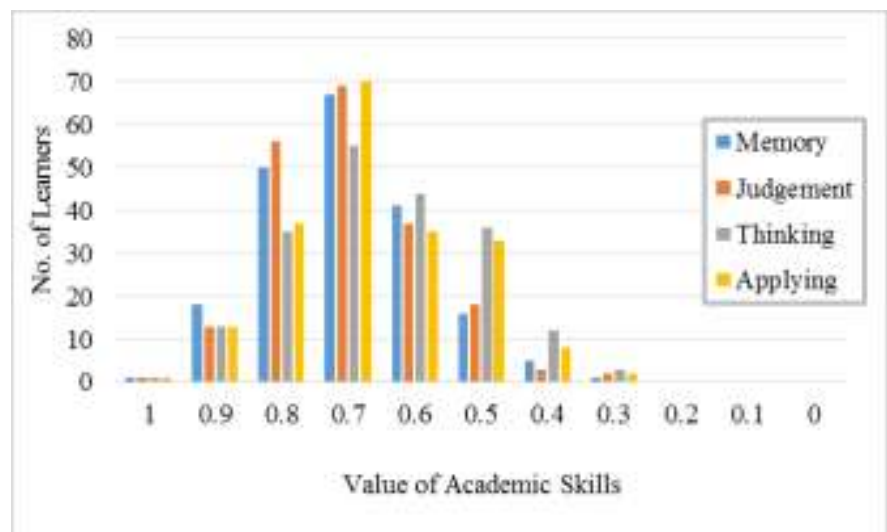

Fig. 4. Bar Chart of Learners' Academic Skills

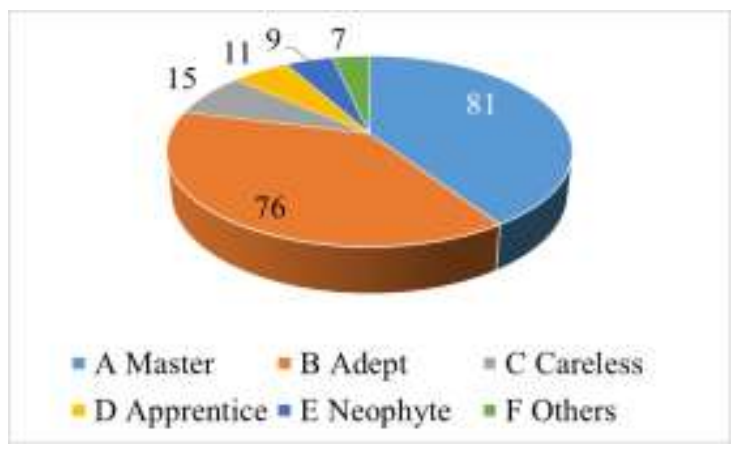

Fig. 5. Classification Result of Type of Learners' Understanding

Fig. 4 illustrates the bar chart of learners' academic skills. The peak of the skills are distributed similarly. It shows the validation of the difficulty and categorization of questions

Fig. 5 shows the classification result of the type of learners' understanding. About $40 \%$ of the learner is classified in the type of "Master" followed by "Adept". We consider the reasons why the rate of "Adept" occupied about 38\% is that the thinking skill was asked in the questions of Applications, that needed to apply basic knowledge to solve. Therefore, many students would be bad at solving the questions.

\section{CONCLUSION AND FuturE WORK}

In this paper, we examined the design and implementation of an e-learning system which consists of three functions, to support IP education. We considered that the difficulty and categorization of the questions was valid for the estimation of learners' understanding by the results. However, the measurement of learners' skills using weights depends on the experiences of the tutor. We would like to make a robust approach by an unsupervised learning method or a mathematical model.

\section{REFERENCES}

[1] B. Bert, M. Bruce, M., and B. Gautam, "Guest Editorial: Special Section on Learning Systems for Science and Technology Education," IEEE Trans. Learn. Technol., vol. 6, no. 3, pp. 194-196, 2013. http://dx.doi.org/10.1109/TLT.2013.30

[2] T. Hsu, C. Chiou, J. C. R. Tseng, and G. Hwang, "Development and Evaluation of an Active Learning Support System for Context-Aware Ubiquitous Learning," Learn. Technol. IEEE Trans., vol. 9, no. 1, pp. 37-45, 2016.
http://dx.doi.org/10.1109/TLT.2015.2439683

[3] H. Murai and H. Okumura, "Assistance of Comprehension by e-Learning," Journal of the educational application of information, vol. 7, no. 1, pp. 31-35, 2004. [published in Japanese]

[4] H. Murai, "Intellectual Property Learning System Supported by SOM," IEICE Technical Report of NLP, vol. 105, no. 547, pp. 113-116, 2006. [published in Japanese]

[5] H. Murai, T. Hayashi, R. Yaegashi, A. Iwaki, and K. Ura, "Development of Gaming App to Support Memorizing Keywords in Law Learning," Technical Report of Japanese Society for Information and Systems in Education, vol. 29, no. 3, pp. 3-6, 2014. [published in Japanese]

[6] H. Murai, T. Hayashi, R. Yaegashi, K. Fujimoto and N. Gotoda, "A Study of Classification of Quizzes on Intellectual-Property Education", Int'l Journal of Computing, Communications \& Instrumentation Engg. (IJCCIE), vol. 3, no. 1, pp. 123-124, 2016. http://dx.doi.org/10.15242/IJCCIE.AE01160012

[7] K. Nakabayashi, "Trends of Technology Standards in Learning Support Systems", Journal of the Japanese Society for Artificial Intelligence, Vol. 17 , No. 4, pp. 465-470, 2002. [published in Japanese]

[8] Bloom, B.S., et al, Taxonomy of Educational Objectives: Handbook I: Cognitive Domain, Longmans, Green and Company, 1956. 